\title{
ARE PATHOGENIC MICRO-ORGANISMS KILLED IN WASTE-DUMPS WHERE SUFFICIENTLY HIGH FERMENTATION TEMPERATURES OCCUR ? ${ }^{1}$ )
}

\author{
J. JANSEN and H. KUNST
}

Institute for Infectious Diseases of the University at Utrecht, Netherlands

Thanks to contact with Mr. J. KIRCH, director of the Public Health Service for Cattle in Noord-Brabant and Ir. B. TEEnsma of the V.A.M., Ltd., Amsterdam (Dutch Company for the Conveyance of Waste), researches could be made as to the killing effect of waste-dumps on pathogenic micro-organisms, especially bacteria.

At Wyster, near Beilen in the province of Drenthe, are four elevated railwaytracks, running parallel. The trains, especially constructed for this purpose, convey large quantities of waste from a number of large towns. The waste is shot on the protracted dumps situated lower than the railway so that after sufficient shoots waste-dumps have been made, about $6 \mathrm{~m}$ thick, $8 \mathrm{~m}$ broad and $475 \mathrm{~m}$ long. Various micro-organisms cause a composting-process in the dumps. This process is checked by continued recording of the temperaturechanges and influenced by watering ( $300 \mathrm{l}$ per ton of waste). In order to obtain an adequate composting-temperature (amounting to $70^{\circ}-90^{\circ} \mathrm{C}$.) certain conditions have to be fulfilled, viz. $1^{\circ}$ ) the waste has to be shot in thick and broad layers so that the heat generated in the waste-heaps accumulates and there are only minimum heat losses by radiation, and $2^{\circ}$ ) the moisture and air conditions in the waste-heap have to be favourable for the development of an intensive bacterial life. It is doubtful whether these conditions are fulfilled in the majority of waste-heaps and it is highly questionable therefore whether they achieve the same high composting-temperatures as at Wyster. Water is being administered nowhere, and in. many places it is customary to spread the waste first in a thin layer, cover it up with a second thin layer after a lapse of time, etc. It is out of the question that high compostingtemperatures occur in a thin layer.

After the composting-process during which very much material perishes a compost has been generated which is very useful for manuring arable land or on reclaimed soil.

\section{STERILIZATION-TESTS}

The question arose whether bacteria from diseased human beings or animals which might occur in such waste could keep alive and give cause to a spreading of diseases when such compost would be used in the fields. We have made a number of tests to this end and, as we were initially ignorant as to the result and the risks involved, we chose for the greater part non-pathogenic germs possessing a resistance corresponding with the pathogenic germs related to them. As the composition of the waste-dumps constructed from summer waste is different from that of winter waste the tests were made in respect of a dump of summer waste as well as one of winter waste.

1) Received for publication January $16,1953$. 


\section{EXPERIMENT IN A SUMMER DUMP}

For the test in the summer dump we selected:

1 Mycobacterium phlei. (This is a micro-organism related to the different types of tubercle bacilli).

2 Salmonella abortus equi. (As representing the very large family of paratyphoid bacilli).

3 Micrococcus aureus. (This is a fairly common agent of festering processes).

4 Bacillus subtilis. (This is a spore-forming micro-organism, related to the anthrax bacillus).

Of the 4 above-mentioned species of bacteria broth-cultures were made. Subsequently 4 tubes were filled with each of these cultures. Two tubes of each culture were dried. Then all 16 tubes were sealed hermetically. Of each species of bacteria one dried and one not-dried tube was kept in our Institute at room-temperature. The other 8 tubes were sealed in a copper vessel. In addition 11 hermetically sealed tubes containing substances, each of which had a different melting-point, were put in the vessel, viz. :

\begin{tabular}{|c|c|c|c|}
\hline 1 & thymol & melting-point & $53^{\circ}$ \\
\hline 2 & diphenylamine & & $54^{\circ}$ \\
\hline 3 & chloral hydrate $\ldots \ldots \ldots \ldots$ & & $57^{\circ}$ \\
\hline 4 & trichlor acetic acid $\ldots$ & $"$ & $59^{\circ}$ \\
\hline 5 & palmitic acid $\ldots \ldots \ldots \ldots$ & " & $64^{\circ}$ \\
\hline 6 & stearic acid $\ldots \ldots \ldots \ldots \ldots$ & " & $70^{\circ}$ \\
\hline 7 & naphthalene & & $81^{\circ}$ \\
\hline 8 & acetamide & " & $82^{\circ}$ \\
\hline 9 & raffinose & & $84^{\circ}$ \\
\hline & salicylic alcohol & & $87^{\circ}$ \\
\hline & meta-nitro-phenol & $"$ & $98^{\circ}$ \\
\hline
\end{tabular}

The vessel was further filled with sand.

On the 12th of September 1949 the vessel was transferred to Wyster and buried into the waste-dump. On the 13th of June 1950 the vessel was unearthed in the presence of Ir. Teensma, his collaborators, Mr. KIRCH and one of us (J). The vessel which had originally been placed at a level of 2.5 metres under the sleepers of the rails proved at the excavation to lie about 3.40 metres deep! The heated waste which had to be dug away was steaming hot. The vessel was easily found. It proved to be almost too hot to handle. On closer inspection the copper container proved to have been little affected if at all, but the lid of galvanised sheet-iron showed some holes by rust. The sand was slightly wet. The newspaper used for wrapping up the different tubes was somewhat discoloured to brown, but still easy to read, soft and somewhat wet. Although the humidity in the vessel was favourable for heat-conduction, it cannot have had any direct influence on the bacteria cultures as they were sealed in glass tubes.

Of the 11 tubes filled with different chemicals for the purpose of ascertaining the maximum-temperature via the melting-points 10 proved to have melted. The melting of the salicylic alcohol in tube 10 proved that the temperature had exceeded $87^{\circ} \mathrm{C}$. The contents of tube 11 (metra-nitro-phenol, meltingpoint $98^{\circ} \mathrm{C}$.) had not melted, but they were somewhat stuck on to the glass wall. So the maximum temperature attained lay between $87^{\circ} \mathrm{C}$. and $98^{\circ} \mathrm{C}$.

All the tubes containing bacteria cultures (the tubes kept in our Institute 
at room-temperature as well as those in the vessel) were opened in exactly the same way. The contents were inoculated into flasks of broth and incubated at $37^{\circ} \mathrm{C}$. The result was as follows :

a. From all the tubes kept at room-temperature the bacteria were grown in pure cultures. The conclusion is therefore that the 4 varieties of bacteria used are not killed when they are kept either in a liquid or in a dry state at room-temperature.

b. The flasks inoculated with the contents of the tubes which had been in the waste-dump remained absolutely sterile. The conclusion is therefore that the 4 micro-organisms used, both in a liquid as well as in a dry state, had died in the waste-heap.

In view of the preceding we consider the conclusion correct that pathogenic micro-organisms, both the spore-forming as well as the non-spore-forming, seem to perish in the dump of summer-waste.

\section{EXPERIMENT IN A WINTER-DUMP}

The test from the winter-waste led to the following report:

In order to facilitate the influence of heat of the dump on the bacteria cultures in this test the cultures were not placed in a wide vessel but in a brass tube with a diametre of $5 \mathrm{~cm}$. This metal tube too was filled up with sand. In the wall of the tube many little holes were made. These served to promote the admission of moisture.

The following micro-organisms were chosen :

1 Mycobacterium phlei.

2 Salmonella typhi-murium. (One of the many important para-typhoid agents).

3 Pseudomonas aeruginosa. (A Gram-negative mobile putrefactive bacillus, sometimes also pathogenic).

4 Bacillus subtilis.

5 Erysipelotrix rhusiopathiae. (A Gram-positive, immobile bacillus, dangerous to human beings, mammals and birds).

Of these 5 different bacilli 2 series were placed in the metal tube; one series consisted of bacteria in liquid medium (broth), the other tubes contained the bacteria in a dried state. (In general the resistance of bacteria in dry surroundings is considerably higher than in wet media). Furthermore a mouse which had died of an infection with E. rhusiopathiae and a mouse which had died of para-typhoid were added, each of them in a sealed container. In addition 2 tubes with cysts of Heterodera rostochiensis were enclosed, about which a statement from an authoritative source will follow later.

In order to obtain an idea of the maximum temperature in the metal tube a series of tubes containing substances each with a different melting-point were added, viz. :

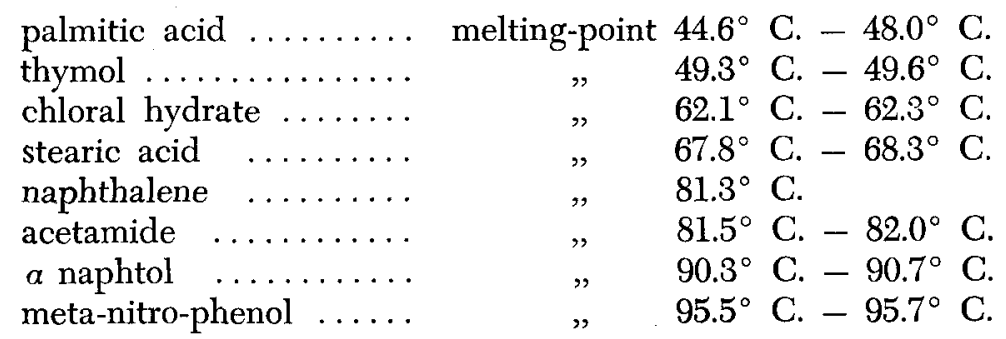


On the 7th of December 1951 the metal tube with its contents was buried in a waste-dump at a depth of 2.5 metres, in the presence again of Ir. TEENSMA, his collaborators, Mr. KIRCH and one of us (J). On the 7th of March 1952, i.e. after having been in the waste-dump for 3 months, the tube was dug up in the presence of Ir. TeEnsma and Mr. KIrch. It was then examined in the Institute for Infectious Diseases at Utrecht.

The palmitic acid, thymol and chloral hydrate had melted, the stearic acid (melting-point $67.8^{\circ}$ C. $-68.3^{\circ}$ C.) had stuck on to the wall.

The substances with a higher melting-point were unchanged. So we estimated the maximum temperature at about $68^{\circ} \mathrm{C}$. Close to the tube a hollow rod had been placed, protruding above the waste-dump. With the aid of a thermometer which was lowered in this auxiliary rod the temperature of the test-tube could be fixed approximatively from time to time. The temperatures observed in this rod were in December $195167^{\circ}-68^{\circ}$ C., in January $195265^{\circ}-72^{\circ} \mathrm{C}$., in February $69^{\circ}-72^{\circ}$ C., in March $67^{\circ}-68^{\circ}$ C. So we may conclude that this result corresponds fairly well with the one given by the other method.

The bacteriological investigation gave the following outcome:

a. From all the controlling-tubes, kept in the Institute, a new growth of the bacteria was obtained.

b. From none of the test-tubes from the waste-dump growth could be obtained with the exception of $B$. subtilis in its dry state. From the B. subtilis in a liquid state no growth was obtained. That the dry B. subtilis spores were not dead need not be wondered at in view of the rather low temperatures developed. Spores, however, occurring scattered in the waste-dump are likely to perish as there they are in a humid medium.

The dead mice had decayed completely. From this mass neither aerobic nor anaerobic cultivation produced any growth. The E. rhusiopathiae- and paratyphoid bacilli and all the other bacteria normally occurring in the intestines of these animals, including many spore-formers (genus Clostridium), consequently proved to have perished completely.

Summarizing we feel entitled to conclude that micro-organisms of a divergent character as employed in our tests, having remained for 3 months in the winterwaste of the dumps at Wyster, have perished.

These two experiments prove in our opinion that it may be taken for granted that germs pathogenic for human beings and animals have perished in both summer and winter waste, provided that care has been taken of proper composting for a sufficiently long period of time. The recordings showed that the temperature in the waste-dump was everywhere the same except in an upper layer of about $20 \mathrm{~cm}$.

In view of that fact we may say that the composting renders the entire enormous waste-dump free from any injurious germs, barring the upper layer. We may suppose that the surface of this uppermost layer is being sterilized by the direct rays of the sun. There is also the possibility that the gasses and vapours arising from the waste-dump kill many pathogenic germs in the uppermost layer. In order to be absolutely certain that all pathogenic germs are killed it is however advisable to turn up the waste-dumps once or twice during the composting. The V.A.M. already does so by means of large claw-cranes.

In this way a compost is obtained which does not contain any germs which could be dangerous to human beings or animals. 